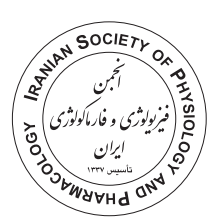

\title{
Short-term regular moderate exercise improved male hypothalamic-pituitary-gonadal axis function via the reduction of hypothalamic neurokinin $\mathrm{B}$ expression in adult rats
}

Nazli Khajehnasiri ${ }^{1}$, Homayoun Khazali², Farzam Sheikhzadeh Hesari ${ }^{3}$, Hamid Reza Sadeghnia ${ }^{4}$, Omid Mehrpour $^{5,6}$, Reihaneh Sadeghian ${ }^{7 *}(\mathbb{D})$

1. Department of Biological Sciences, Faculty of Basic Sciences, Higher Education Institute of Rab-Rashid, Tabriz, Iran

2. Department of Biological Sciences and Technology, Shahid Beheshti University, Tehran, Iran

3. Department of Animal Sciences, Faculty of Biological Sciences, University of Tabriz, Tabriz, Iran

4. Department of Pharmacology, Faculty of Medicine, Mashhad University of Medical Sciences, Mashhad, Iran

5. Arizona Poison \& Drug Information Center, University of Arizona, College of Pharmacy and University of Arizona, Tucson, AZ, USA

6. Medical Toxicology and Drug Abuse Research Center, Birjand University of Medical Sciences, Birjand, Iran

7. Medical Plants Research Center, Shahrekord University of Medical Sciences, Shahrekord, Iran

\begin{abstract}
Introduction: In the arcuate nucleus, kisspeptin, neurokinin-B and pro-dynorphin (KNDy) neurons control the function of gonadotropin-releasing hormone $(\mathrm{GnRH})$ neurons. Early investigations indicated that exercise with various intensities affects luteinizing hormone (LH) and testosterone (T) in different ways. Meanwhile the molecular mechanisms underlying its function not yet been fully understood. Accordingly, the present study evaluated the role of alterations in the levels of KNDy mRNA upstream of GnRH neurons in conveying the effects of various short-term exercise intensities on the male hypothermicpituitary-gonadal (HPG) axis.

Methods: Twenty-one adult Wistar rats were randomly divided into 3 groups: control, onemonth regular moderate exercise (ME) and one-month regular intensive exercise (IE). In $\operatorname{ME}(22 \mathrm{~m} / \mathrm{min})$ and IE $(35 \mathrm{~m} / \mathrm{min})$ groups, the rats were treated 5 days a week for $60 \mathrm{~min}$ each day. Finally, we assessed serum levels of LH and T using the ELIZA technique and KNDy and Gnrh mRNA expression by the real-time PCR method.

Results: The results revealed that in ME group the expression of $N k b$ was reduced and the expression of Gnrh mRNA and the LH and T serum levels were increased. However, intensive exercise did not change the serum levels of $\mathrm{LH}$ and $\mathrm{T}$ or the relative expression of kiss l, Nkb, Pdyn and Gnrh genes.

Conclusion: The results suggested that monthly moderate exercise improved male reproductive axis function, while intensive exercise did not have an adverse effect on the reproductive axis. These various effects on the male HPG axis may be propagated by the change in hypothalamic $N k b$ gene expression.
\end{abstract}

\footnotetext{
* Corresponding author: Reihaneh Sadeghian, sadeghian.r@skums.ac.ir

Received 14 February 2020; Revised from 30 September 2020; Accepted 11 November 2020
}

Citation: Khajehnasiri N, Khazali H, Sheikhzadeh Hesari F, Sadeghnia H.R., Mehrpour O, Sadeghian R. Medical Plants Research Center, Shahrekord University of Medical Sciences, Shahrekord, Iran. Short-term regular moderate exercise improved male hypothalamic-pituitary-gonadal axis function via the reduction of hypothalamic neurokinin B expression in adult rats. Physiology and Pharmacology 2021; 25: 171-177. http://dx.doi.org/10.32598/ppj.25.2.20 


\section{Introduction}

Kisspeptin is a 54-amino acid peptide, encoded by the Kiss1 gene (Dhillo et al., 2005; Kotani et al., 2001) which activates the orphan $\mathrm{G}$ protein-coupled receptor GPR54 (Kotani et al., 2001). Evidence suggests that the kisspeptin/GPR54 system has an important role in reproduction and kisspeptin has been introduced as an afferent neuron of the gonadotropin-releasing hormone (GnRH) neurons (Kalló et al., 2012; Lehman et al., 2010). In rodents, the kisspeptin neurons are in two separate parts of the hypothalamus, the arcuate nucleus and the anteroventral periventricular nucleus (Chaikhun et al., 2013). In addition to the kisspeptin, neurokinin-B (NKB) and pro-dynorphin (Pdyn) are co-expressed by arcuate kisspeptin neurons; because of that, they are called KNDy (Lehman et al., 2010).

Glucocorticoid, steroids, opioids (such as kappa opioid receptor) and neurokinin-B receptors are found in large numbers on KNDy neurons (Chaikhun et al., 2013; Pinilla et al., 2012). Note that only a small number of kisspeptin receptors are available on KNDy neurons (Pinilla et al., 2012). The existence of multiple receptors on KNDy neurons and the transfer of the KNDy neuronal projections to the hypothalamic-preoptic area and the zone of the median eminence indicate the pivotal role of these neurons in transmitting signals to the GnRH neurons (Lehman et al., 2010).

Previous studies have suggested that exercise can result in altered levels of luteinizing hormone (LH) and testosterone (Hackney 2020), but there are conflicting results about the effects of exercise on the reproductive axis. For example, it has been shown that testosterone or estradiol increases with acute bouts of exercise, but other evidence has shown lower testosterone in male endurance athletes (Sokoloff et al., 2016). However, 16 weeks of $150 \mathrm{~min}$ per week of moderate aerobic exercise in premenopausal women did not significantly alter the sex hormone (Smith et al., 2011). It seems that the type and duration of exercise are important factors affecting reproductive performance. However, the molecular mechanisms of these effects are unknown (Homan et al., 2007).

Therefore, in considering the fundamental roles of the GnRH neurons in the hypothermic-pituitary-gonadal (HPG) axis, along with the necessary roles of KNDy neurons in conveying the internal and external signals to GnRH neurons and altering the reproductive axis, the present study investigated the changes in hypothalamic neuropeptide gene expression to discover the main hypothalamic pathway that influences the HPG axis functions during the one-month regular moderate exercise.

\section{Material and methods}

\section{Animals and exercise protocol design}

Twenty-one male Wistar rats $(250 \pm 50 \mathrm{~g})$ were purchased from the Pasteur Institute, Tehran, Iran. The rats were maintained at a controlled temperature of $22 \pm 2^{\circ} \mathrm{C}$ in a 12-hour light/dark cycle and were given free access to food and water.Allprocedures for maintaining and using experimental animals were performed according to the guide for the care and use of laboratory animals (NIH Guide for Care and Use of Laboratory Animals, $8^{\text {th }}$ Edition, 2010) and accepted by the Ethics Committee of the Shahrekord University of Medical Sciences (IR.SKUMS.REC.1398.195). The animals were randomly distributed into three groups ( $\mathrm{n}=7$ in each group): 1, control, 2, one-month regular moderate exercise (ME) and 3, one-month regular intensive exercise (IE).

After 5 days of habituation, therats scheduled fortraining were exercised on a rodent treadmill (at 0 inclination) 5 days a week, for 4 weeks. The treadmill speed was $16 \mathrm{~m} / \mathrm{min}$ during the first week, was increased and kept at $22 \mathrm{~m} / \mathrm{min}$ (ME) or $35 \mathrm{~m} / \mathrm{min}$ (IE) for the remaining training sessions. The session duration started at $40 \mathrm{~min} /$ day and was increased by $5 \mathrm{~min}$ daily. During the last 3 weeks, the rats ran for $1 \mathrm{~h}$ daily. It should be noted that all exercised rats were treated before 12AM. The control group were not exercising, but they were put on a nonmoving treadmill 5 days a week for $60 \mathrm{~min} /$ day. All tests for hormones were performed in the morning (Hesari et al., 2014; Khajehnasiri et al., 2019 ).

Biochemical assay and determination of the levels of LH and testosterone

Twenty-four hours after the last exercise session, all the rats were anesthetized through injection of $100 \mathrm{mg} /$ $\mathrm{kg}$ ketamine and $10 \mathrm{mg} / \mathrm{kg}$ xylazine intraperitoneally (Shahidi et al., 2019; Shahidi et al., 2018). Next, blood samples were collected from the eye sinus for determination of LH and testosterone, where the serum was separated accordingly. Finally, we used Bioassay Science Laboratory's ELISA kit to assess the LH (Bioassay Technology Laboratory- E0179Ra, China) and tes- 
tosterone levels (Bioassay Technology Laboratory E0179Ra, China).

Molecular assay and determination of the levels of Kiss 1, Nkb, Pdyn, and Gnrh gene expressions

For evaluation molecular test, an arcuate nucleus was extracted from the brain hypothalamus based on a previous method (Khajehnasiri et al., 2018; Molaei et al., 2020). Briefly, YTzol Pure RNA buffer (Yekta Tajiz, Iran) removed total RNAs from samples. Next, the Nanodrop measured their concentration and purity. Eventually, for synthesis of cDNA a reverse transcription kit (BIONEER, Korea) was used.

The triplicate reactions utilized for estimating Kiss 1, $N k b, P d y n$, and Gnrh gene expressions were conducted on cDNA specimens via gene-specific primers, as reported in Table 1. Then, real-time PCR was done by the SYBR Green PCR Master Mix (Takara Bio Inc., Japan). Note that PCRs served as the negative controls for each primer set in the absence of template cDNAs. The reaction was incubated for $5 \mathrm{~min}$ at $95^{\circ} \mathrm{C}$ followed by 45 cycles of PCR for 30 s at 95,60 and $72^{\circ} \mathrm{C}$ for each and a final extension step at $72{ }^{\circ} \mathrm{C}$ for $5 \mathrm{~min}$. At the end of the PCR reaction, each amplicon produced a single peak, whereas they did not present any peaks when there was no template (Schmittgen and Livak 2008).

Statistical analyses
The data related the real-time PCR analyzed via the comparative $\mathrm{Ct}$ procedure, while the relative expression of the target genes over reference were values determined using the arithmetic formula $2^{-\Delta \Delta \mathrm{CT}}$. Then, the Kolmogorov-Smirnov normality test was used to see whether the collected data on the relative expression of target genes and LH and testosterone serum levels were normally distributed or not. At last, the experimental data were assayed by SPSS version 16.0. One-way ANOVA with posthoc Tukey test was utilized to compare the performance of the three groups. The significance level was considered to be $P<0.05$.

\section{Results}

Gnrh expression in response to one-month regular moderate and intensive exercise

The one-way ANOVA showed that one-month regular moderate exercise elevated the Gnrh mRNA levels $(P<0.05)$. However, one-month regular intensive exercise treatment was not adequate to create noticeable changes in gene expression ( $P=0.082$; Fig. 1$)$.

Arcuate Nkb, Kissl and Pdyn gene expression in response to one-month regular moderate and intensive exercise

Next, real-time PCR analysis was used to determine the effect of one-month regular moderate and intensive

TABLE 1: The sequence of the primers used in this study

\begin{tabular}{|c|c|c|c|}
\hline Gene & Forward & Reverse & Amplicon (bp) \\
\hline Gapdh & 'CGGCCAAATCCGTTCACACCGA3'5 & 'GGCTCTCTGCTCCTCCCTGTTC3‘5 & 122 \\
\hline Kiss1 & AGCCAGATAGAGGAAGCCCAGG’3‘5 & CCACACAGAGGAGCAGCAG’3‘5 & 182 \\
\hline Pdyn & ACAAAGCAGCACGCAGGTCAC’3‘5 & TCAGAGGGGATCACAAGGAGG’3‘5 & 144 \\
\hline $\mathrm{Nkb}$ & CAAGAGGAACAGCCAACCAG’3‘5 & AAGGGAGCCAACAGGAGGAC’3‘5 & 199 \\
\hline Gnrh & GCCGCTGTTGTTCTGTTGACTG’3‘5 & ССТССТССТTGCCCATCTCTTG’3‘5 & 131 \\
\hline
\end{tabular}

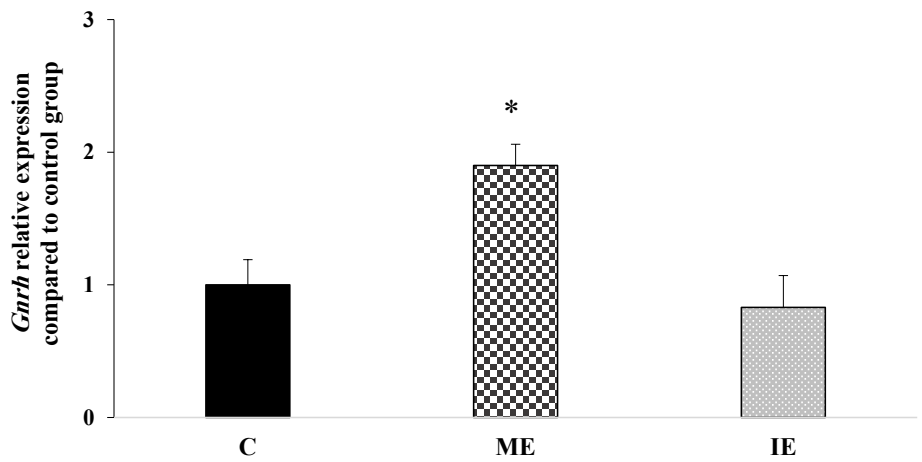

FIGURE 1. Effect of short-term moderate and intensive regular exercise on Gnrh gene expression in arcuate nucleus of hypothalamus. Control $(\mathrm{C})$, one-month regular moderate exercise (ME) and one-month regular intensive exercise (IE) groups. Data are displayed as mean $\pm \mathrm{SD}$. ${ }^{*} P<0.05$ compared with control group. Containing 7 rats in each group. 


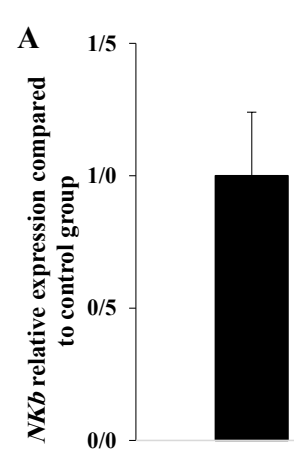

C

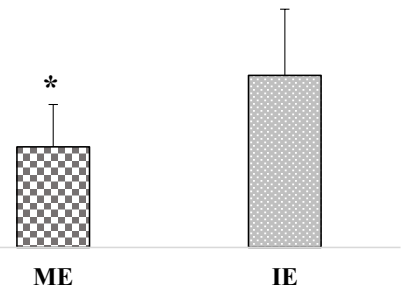

ME
B

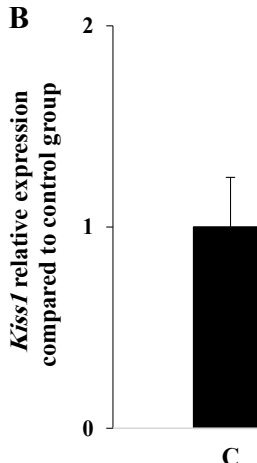

C

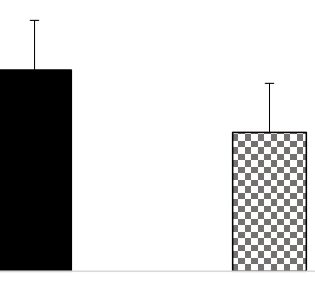

ME

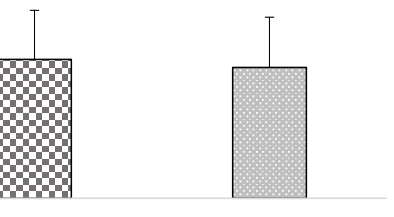

IE

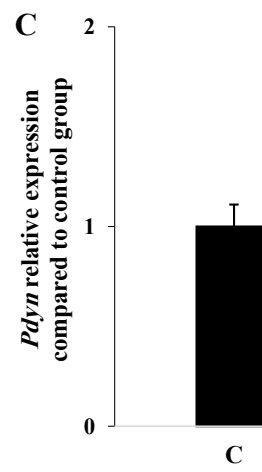

C

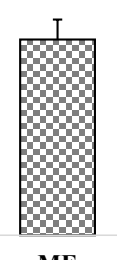

ME

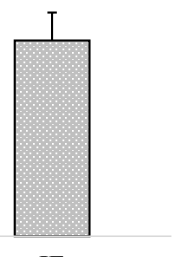

IE

FIGURE 2. Effect of short-term moderate and intensive regular exercise on $N k b$ (A), Kiss 1 (B) or Pdyn (C) expression in arcuate nucleus of hypothalamus. Containing 7 rats in each group, Control (C), one-month regular moderate exercise (ME) and one-month regular intensive exercise (IE) groups. Data are displayed as mean $\pm \mathrm{SD}$. ${ }^{*} P<0.05$ compared with control group.
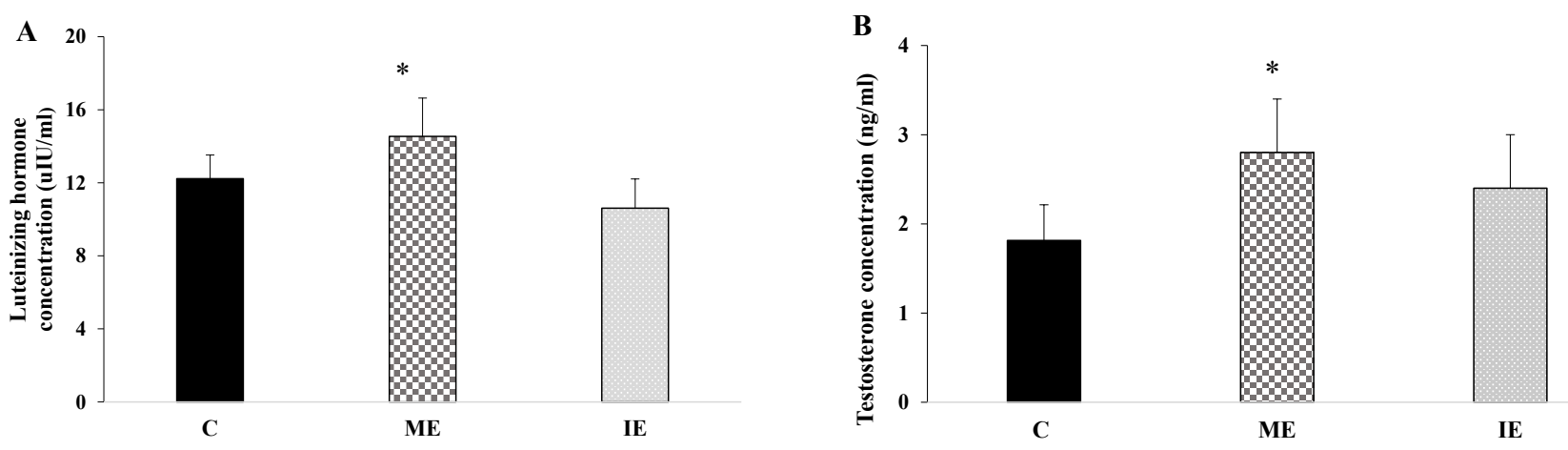

FIGURE 3. (A) Effect of short-term moderate and intensive regular exercise on luteinizing hormone and (B) testosterone serum levels. Control (C), one-month regular moderate exercise (ME) and one-month regular intensive exercise (IE) groups. Containing 7 rats in each group. Data are displayed as mean $\pm \mathrm{SD} .{ }^{*} P<0.05$ compared with control group.

exercise on arcuate Kiss $1, N k b$ and $P d y n$ gene expressions (known as the key HPG axis regulators). The ME group presented a significant decline in the $N k b$ mRNA level, compared to the control group $(P<0.05$; Fig. $2 \mathrm{~A})$. However, there was no difference in the arcuate Kiss 1 $(P=0.071)$ and $P d y n(P=0.95)$ mRNA levels between the moderate exercise and control groups (Figs. $2 \mathrm{~B}$ and C). No difference was observed either in $N k b(P=0.71)$, Kiss1 $(P=0.10)$ and Pdyn $(P=0.92)$ mRNA expression in the IE rats, compared to control (Figs. 2A-C; Table2).

\section{LH and testosterone serum concentrations}

Finally, reproductive performance indicators (LH and testosterone serum levels) were tested in response to one-month regular moderate and intensive exercise by the ELISA method. The LH $(14.54 \pm 2.1 \mathrm{uIU} / \mathrm{ml}$; $P<0.05)$ and testosterone $(2.8 \pm 0.6 \mathrm{ng} / \mathrm{ml} ; \quad P<0.05)$ serum concentrations significantly increased in $\mathrm{ME}$ exercised group, compared with concentrations in the control group of testosterone $(1.8 \pm 0.4 \mathrm{ng} / \mathrm{ml})$ and $\mathrm{LH}$ (12.22 $\pm 1.3 \mathrm{uIU} / \mathrm{ml}$, Table 3). However, no difference was observed in the $\mathrm{LH}\left(10.6 \pm 1.6 \mathrm{uIU} / \mathrm{ml} ; P_{=} 0.072\right)$ and testosterone $(2.4 \pm 0.0 .6 \mathrm{ng} / \mathrm{ml} ; P=0.059)$ serum levels between IE and control rats (Figs. 3A and B). 


\begin{tabular}{|c|c|c|c|}
\hline & Control & ME & IE \\
\hline Gnrh & 1 & $1.9^{*}$ & 0.83 \\
\hline Kiss 1 & 1 & 0.69 & 0.65 \\
\hline$N k b$ & 1 & $0.38^{*}$ & 0.61 \\
\hline$P d y n$ & 1 & 0.98 & 0.94 \\
\hline
\end{tabular}

\begin{tabular}{|c|c|c|c|}
\hline & Control & ME & IE \\
\hline LH & $12.22 \pm 1.3$ & $14.54 \pm 2.1 *$ & $10.61 \pm 1.6$ \\
\hline $\mathrm{T}$ & $1.81 \pm 0.4$ & $2.80 \pm 0.6^{*}$ & $2.4 \pm 0.6$ \\
\hline
\end{tabular}

\section{Discussion}

Our findings revealed that the Gnrh mRNAlevel did not change following IE, but the moderate exercise induced siderable increase in the expression of the Gnrh gene. Note that these alterations in Gnrh expression coincided with changes in the serum LH and testosterone levels across all experimental groups. The early study demonstrated that several physiological factors both directly and indirectly relay their impacts on GnRH neurons; therefore, short-term regular moderate and intensive exercises may exert their effects directly or indirectly. Numerous studies have addressed the role of KNDy neurons in reproduction and have emphasized the key role of this neuropeptide in projecting the effects of various factors on releasing $\mathrm{GnRH} / \mathrm{LH}$ (Amodei et al., 2020; Yeo and Colledge 2018). Accordingly, the present research studied changes in the mRNA level of the arcuate neuropeptide (upstream of GnRH neurons) in response to short-term moderate and intensive physical activity. Our results indicate that some changes occurred in the expression of genes involved in regulating the neuronal function of GnRH and subsequently in the performance of the reproductive axis, in response to short-term moderate and intensive exercise. In addition, the results provide a new perspective for understanding the reason for reproductive hormonal alteration in response to exercise. Our data show that only NKB neuropeptide was significantly altered in response to short-term regular moderate exercise; therefore, NKB had a role in conveying the effect of one-month regular moderate physical activity on the hypothalamicpituitary-gonadal axis.

The ME decreased $N k b$ mRNA level while intensive exercise did not influence the $N k b$ mRNA level. Thus, different intensities of short-term exercise had various effects on $N k b$ mRNA levels. Accordingly, based on the findings, the arcuate $N k b$ mRNA level was mainly associated with the exercise intensity rather than its duration. Concerning the effect of moderate exercise for one month, these results are similar to the findings of our previous study, in which treatment of rats with moderate exercise for six months decreased $N k b$ mRNA expression in the arcuate nucleus (Khajehnasiri et al., 2018).

On the other hand, although recent studies in rodents have reported contradictory effects of the NKB on GnRH and LH secretions (Rance et al., 2010), most of the investigations have suggested that the NKB had an inhibitory effect on LH secretion in rodents with high levels of sex steroid hormones. The NKB agonist acted as an inhibitor of LH secretion in both rats and mice (Amodei et al., 2020; Chaikhun et al., 2013; Grachev et al., 2012).

The opposite effect of NKB has been observed under the conditions of low levels of sex steroid hormones (Salehi et al., 2012). In the current study, the $N k b$ gene expression diminished in the ME group, where this reduction was consistent with elevation of $\mathrm{LH}$ and testosterone serum levels. Thus, the present results 
confirmed the NKB inhibitory effect on the LH secretion in rodents. Moderate exercise may reduce the inhibitory effects of the NKB on GnRH neurons, effects that were followed by an increase in the $\mathrm{LH}$ and testosterone hormone levels. These findings are in line with the outcomes obtained by many researchers who report that moderate exercise has beneficial effects on the pituitarygonadal axis (Di Luigi et al., 2012; Grandys et al., 2009).

According to the obtained data, $P d y n$ gene expression was not affected by short-term moderate and intensive exercise. However, our previous study suggested that long-term intensive and moderate exercise caused enhanced Pdyn mRNA expression in the arcuate nucleus (Khajehnasiri et al., 2018). Consequently, based on this finding, the arcuate Pdyn mRNA level was mostly associated with the exercise duration rather than its intensity. Numerous studies have described the inhibitory function of $P d y n$ neuropeptide released from KNDy neurons on GnRH/ LH (Lehman et al., 2010). No change in Pdyn gene expression, as an inhibitory factor of reproduction, in rats after moderate exercise could be another reason for the LH- and testosteronelevel evaluation.

The Kiss 1 gene expression in the regular moderateand intensive-exercise groups showed no significant difference, compared to control rats. Khajehnasiri et al. (2018) reported that long-term physical activity can not alter Kiss 1 gene expressions, which is in line with present results. Therefore, these findings indicated that kiss 1 mRNA level was not affected by different intensity and duration of physical activity.

\section{Conclusion}

Overall, our results indicate that one-month moderate exercise improves the male HPG function through reduction of $N k b$ gene expression. On the other hand, one-month intensive exercise does not have a distractive effect on the reproduction axis as $\mathrm{LH}$ and testosterone serum levels remain unchanged in response to onemonth regular intensive exercise.

\section{Acknowledgment}

This study did not obtain any grant.

\section{Conflict of interest statement}

The authors state no conflict of interest.

\section{Reference}

Amodei R, Gribbin K, He W, Lindgren I, Corder KR, Jonker SS, et al. Role for kisspeptin and neurokinin B in regulation of luteinizing hormone and testosterone secretion in the fetal sheep. Endocrinology 2020; 161. https://doi. org/10.1210/endocr/bqaa013

Chaikhun T, Sotthibandhu P, Suadsong S. The role of kisspeptin signaling in reproduction of ruminant. Thai Vet Med 2013; 43: 7-14. https://he01.tci-thaijo.org/index.php/tjvm/ article/view/9455

Dhillo WS, Chaudhri OB, Patterson M, Thompson EL, Murphy $\mathrm{KG}$, Badman MK, et al. Kisspeptin-54 stimulates the hypothalamic-pituitary gonadal axis in human males. J Clin Endocrinol Metab 2005; 90: 6609-15. https://doi. org/10.1210/jc.2005-1468

Di Luigi L, Romanelli F, Sgro P, Lenzi A. Andrological aspects of physical exercise and sport medicine. Endocrine 2012; 42: 278-84. https://doi.org/10.1007/s12020-0129655-6

Grachev P, Li XF, Lin YS, Hu MH, Elsamani L, Paterson $\mathrm{SJ}$, et al. GPR54-dependent stimulation of luteinizing hormone secretion by neurokinin B in prepubertal rats. PLoS One 2012; 7: e44344. https://doi.org/10.1371/journal. pone. 0044344

Grandys M, Majerczak J, Duda K, Zapart-Bukowska J, Kulpa J, Zoladz JA. Endurance training of moderate intensity increases testosterone concentration in young, healthy men. Int J Sports Med 2009; 30: 489-95. https://doi. org/10.1055/s-0029 1202340

Hackney AC. Hypogonadism in exercising males: dysfunction or adaptive-regulatory adjustment? Front endocrinol 2020; 11: 11. https://doi.org/10.3389/fendo.2020.00011

Hesari FS, Khajehnasiri N, Khojasteh SM, Soufi FG, Dastranj A. Attenuation of phosphorylated connexin-43 protein levels in diabetic rat heart by regular moderate exercise. Arch Iran Med 2014; 17: 569-73. http://eprints.hums.ac.ir/ $\mathrm{id} /$ eprint $/ 2480$

Homan GF, Davies M, Norman R. The impact of lifestyle factors on reproductive performance in the general population and those undergoing infertility treatment: a review. Hum Reprod Update 2007; 13: 209-23. https://doi.org/10.1093/ humupd/dml056

Kallo I, Vida B, Deli L, Molnar CS, Hrabovszky E, Caraty A, et al. Co-localisation of kisspeptin with galanin or neurokinin B in afferents to mouse GnRH neurones. J Neuroendocrinol 2012; 24: 464-76. https://doi.org/10.1111/j.13652826.2011.02262.x 
Khajehnasiri N, Khazali H, Sheikhzadeh F. Various responses of male pituitary-gonadal axis to different intensities of long-term exercise: Role of expression of KNDYrelated genes. J Biosci 2018; 43: 569-74. https://doi.org/10.1007/s12038-018-9782-1

Khajehnasiri N, Khazali H, Sheikhzadeh F, Ghowsi M. Onemonth of high-intensity exercise did not change the food intake and the hypothalamic arcuate nucleus proopiomelanocortin and neuropeptide $\mathrm{Y}$ expression levels in male Wistar rats. Endocr Regul. 2019 53(1):8-13. https://doi. org/10.2478/enr-2019-0002

Kotani M, Detheux M, Vandenbogaerde A, Communi D, Vanderwinden JM, Le Poul E, et al. The metastasis suppressor gene KiSS-1 encodes kisspeptins, the natural ligands of the orphan G protein-coupled receptor GPR54. J Biol Chem 2001; 276: 34631-6. https://doi.org/10.1074/jbc. M104847200

Lehman MN, Coolen LM, Goodman RL. Minireview: kisspeptin/neurokinin B/dynorphin (KNDy) cells of the arcuate nucleus: a central node in the control of gonadotropin-releasing hormone secretion. Endocrinology 2010; 151: 3479-89. https://doi.org/10.1210/en.2010-0022

Molaei A, Hatami H, Dehghan G, Sadeghian R, Khajehnasiri $\mathrm{N}$. effects of quercetin and regular exercise on the recovery of spatial memory and reduction of parameters of oxidative stress in animal model of Alzheimer's disease. Excli j 2020; 19: 596-612.

Pinilla L, Aguilar E, Dieguez C, Millar RP, Tena-Sempere M. Kisspeptins and reproduction: physiological roles and regulatory mechanisms. Physiol Rev 2012; 92: 1235-316. https://doi.org/10.1152/physrev.00037.2010

Rance NE, Krajewski SJ, Smith MA, Cholanian M, Dacks PA. Neurokinin B and the hypothalamic regulation of reproduction. Brain Res 2010; 1364: 116-28. https://doi. org/10.1016/j.brainres.2010.08.059
Salehi MS, Namavar MR, Shirazi MR, Rahmanifar F, Tamadon A. A simple method for isolation of the anteroventral periventricular and arcuate nuclei of the rat hypothalamus. Anatomy 2012; 7. https://doi.org/10.2399/ana.11.212

Schmittgen TD, Livak KJ. Analyzing real-time PCR data by the comparative C(T) method. Nat Protoc 2008; 3: 1101-8. https://doi.org/10.1038/nprot.2008.73

Shahidi S, Komaki A, Sadeghian R, Asl SS. Different doses of methamphetamine alter long-term potentiation, level of BDNF and neuronal apoptosis in the hippocampus of reinstated rats. J Physiol Sci 2019a; 69: 409-19. https://doi. org/10.1007/s12576-019-00660-1

Shahidi S, Sadeghian R, Komaki A, Asl S S. Intracerebroventricular microinjection of the 5-HT1F receptor agonist LY 344864 inhibits methamphetamine conditioned place preference reinstatement in rats. Pharmacol Biochem Behav 2018; 173: 27-35. https://doi.org/10.1016/j. pbb.2018.08.001

Smith AJ, Phipps WR, Arikawa AY, O’Dougherty M, Kaufman B, Thomas W, et al. Effects of aerobic exercise on premenopausal sex hormone levels: results of the WISER study, a randomized clinical trial in healthy, sedentary, eumenorrheic women. Cancer Epidemiol Biomarkers Prev 2011; 20: 1098-106. https://doi.org/10.1158/1055-9965. EPI-10-1219

Sokoloff NC, Misra M, Ackerman KE. Exercise, training, and the hypothalamic-pituitary-gonadal axis in men and women. Front Horm Res 2016; 47: 27-43. https://doi. org/10.1159/000445154

Yeo SH, Colledge WH. The role of Kiss1 neurons as integrators of endocrine, metabolic, and environmental factors in the hypothalamic-pituitary-gonadal axis. Front Endocrinol (Lausanne) 2018; 9: 188. https://doi.org/10.3389/fendo. 2018.00188 